\title{
AÇÃO DE AGENTES QUÍMICOS E FÍSICOS SOBRE OVOS DE Lagochilascaris minor. (Leiper,1909).
}

\author{
Jayrson Araújo de Oliveira ${ }^{*}$, Miguel Alipio Vieira ${ }^{* *}$, Andréa Caetano da Silva ${ }^{* *}$, \\ Carlos Augusto Lopes Barbosa**, Aline Pinheiro Veloso
}

\section{RESUMO}

Ovos recém-eliminados em fezes de gatos infectados experimentalmente com Lagochilascaris minor foram testados quanto à ação de vários agentes químicos (álcool etílico, hipoclorito, formaldeído e lugol em várias concentraçø̃es) e agentes físicos (congelamento $-10^{\circ} \mathrm{C}$, aquecimento $80 / 97^{\circ} \mathrm{C}$ ) para se verificar o indice de letalidade através do percentual de embriogênese. Estes ovos foram colocados sob a ação desses agentes por um período de 24 horas. Após este período foram lavados por 3 vezes em água destilada e mantidos em placas de Petri com solução de formaldeído $1 \%$ por 45 dias em temperatura ambiente. Todos os ovos foram examinados entre lâminas e lamínulas ao microscópio óptico, $\mathrm{O}$ aquecimento a $90^{\circ} \mathrm{C}$, álcool etílico a $99 \%$, lugol $(100 \%, 50 \%, 25 \%, 12,5 \%, 6,25 \%, 3,125 \%)$ apresentaram o índice de letalidade de $100 \%$.

UNITERMOS: Lagochilascaris minor, agentes químicos e físicos, ovos de helmintos.

\section{INTRODUÇÃO}

No Brasil, as parasitoses intestinais transmitidas por helmintos, assumem um papel relevante em face ao elevado índice de prevalência, tanto pelo aspecto médico social, como pelo aspecto epidemiológico, diante das implicações clínicas e dos prejuízos causados aos seres humanos.

Vários autores têm relatado a presença de patógenos em rede de esgotos apresentando elevada resistência aos processos de tratamentos e persistindo por longos períodos. $^{(2,3,6,7,8,9)}$ Em nosso país, são poucas as cidades que fazem tratamentos da

\footnotetext{
Técnico de Laboratório do Depto. Parasitologia, IPTSP/UFG

*. Prof. do Depto. de Parasitologia, IPTSP/UFG

-*Bsista de Iniciação Científica, $\mathrm{CNPq}$

Recebido para publicação em 19/09/95
} 
OLIVEIRA, J.A.; VIEIRA, M.A.; SILVA, A.C.; BARBOSA, C.A.L.; VELOSO, A.P. Ação de agentes ( 2 ): $301-311$, quimicos e fisico

rede de esgotos. A concentração destes contaminantes biológicos nos esgotos domésticos é influenciada por fatores como: condições de saúde da população e presença de estações de tratamento desses esgotos.

A elevada resistência de ovos de helmintos, especialmente de Ascarídeos, frente aos vários processos de tratamentos como, altas temperaturas, reagentes químicos e dessecação são relatados na literatura $(3,6,7,9)$. Alguns agentes químicos e físicos apresentam ação larvicida sobre ovos de helmintos inclusive com destruição dos mesmos $(1,3,6,9)$

O Lagochilascaris minor é um ascarídeo raro entre humanos e animais domésticos como o gato e o cão. Seu ciclo experimental proposto por CAMPOS et al, ${ }^{(4)}$ utilizando camundongos como hospedeiros intermediários e gatos como hospedeiros definitivos, vem sendo mantido no Departamento de Parasitologia do IPTSP/UFG Tanto na lagochilascaríase humana como na experimental pode-se observar a presença de diferentes fases evolutivas no local das lesões (ovos, larvas e vermes adultos) ${ }^{(4)}$. Na manutenção deste ciclo evolutivo experimental são encontrados ovos nas fezes de gatos infectados e são utilizadas para obtenção de cultura de ovos, que serão posteriormente inoculados em camundongos. Durante este processo de produção de culturas, vários ovos são eliminados e jogados diretamente na rede de esgotos, podendo ser infectantes para alguns animais ou mesmo para o homem, pois neste, ainda não se sabe o mecanismo de infecção.

Vários autores têm mostrado a importância da disseminação de ovos através de esgotos, daí a preocupação na elaboração deste trabalho, cujo objetivo foi, avaliar ação dos agentes químicos e físicos e dimimuir os custos gastos na esterilização dos dejetos e materiais contaminados com ovos de Lagochilascaris minor, para que os mesmos possam ser eliminados sem causar riscos à população, haja visto que em nossa comunidade não existe tratamento da rede de esgotos.

\section{MATERIAL E MÉTODOS}

\section{Obtenção dos ovos}

Os ovos foram obtidos a partir de fezes de gatos infectados experimentalmente com Lagochilascaris minor, por sedimentação espontânea após sucessivas lavagens em água e pelo método de Faust ${ }^{(5)}$. Esses ovos foram transferidos para tubos de ensaios graduados, retiravam-se 5 aliquotas de $0,01 \mathrm{ml}$ e colocavam-se entre lâmina e lamínula, e com o auxílio de microscopia óptica, procedia-se a contagem. A média das 5 contagens determinava a concentração de ovos por ml. Esses ovos foram transferidos
OLIVEIRA, J.A.; VIEIRA, M.A.; SILVA, A.C.; BARBOSA, C.A.L.; VELOSO, A.P. Ação de agentes químicos e físicos sobre ovos de Lagochilascaris minor. Leiper,1909. Rev. Pat. Trop.24 ( 2 ): 301 - 311 , jul/dez. 1995

para tubos de ensaio na concentração de $10^{4}$ ovos/tubo e testados frente a diferentes agentes químicos ou físicos por um período de 24 horas. A escolha, deste número de ovos, foi devido ao fato de ser uma parcela significativa que representa a eliminação diária de ovos nas fezes dos gatos infectados.

\section{Agentes químicos}

1-Formaldeído PA-(37\%, 30\%, 20\%, 10\%, 5\%)

2-Formaldeído comercial a $5 \%$

3-Álcool etílico PA-(99\%, 90\%, 80\%, 70\%)

4-Hipoclorito de Sódio-(6,13 N; 4,0 N; 3,0 N; $2,0 \mathrm{~N} ; 1,0 \mathrm{~N} ; 0,5 \mathrm{~N})$

5 -Lugol-(100\%; 50\%; 25\%; 12,5\%; 6,25\%; 3,125\%)

6-Sulfato de Zinco (33\%)

\section{Agentes físicos}

1-Congelamento em freezer a $-10^{\circ} \mathrm{C}$

2-Aquecimento a $80{ }^{\circ} \mathrm{C}, 90^{\circ} \mathrm{C}, 97^{\circ} \mathrm{C}$ com a introdução de água aquecida nos tubos de ensaio contendo ovos.

Após 24 horas em contato com os agentes físicos e químicos, esses ovos foram lavados em água por três vezes consecutivas, transferidos para placas de Petri contendo solução de formaldeído a $1 \%$ e deixados por um período de 45 dias à temperatura ambiente, para observar se haveria evolução. Decorrido este período, os ovos foram centrifugados, o sobrenadante descartado, diluídos em água, e desta suspensão foram coletadas 3 alíquotas de $0,05 \mathrm{ml}$ que foram colocadas entre lâmina $\mathrm{e}$ lamínula, examinadas e contado ao microscópio óptico o número de ovos férteis e inférteis. A fertilidade dos ovos era avaliada pela compressão entre lâmina e lamínula sendo que se a larva tivesse mobilidade era considerada fértil.

\section{Grupos controle}

Para cada agente testado, foram feitos grupos controle, constituídos por $10^{4}$ ovos pré-embrionados que foram transferidos para placas de Petri contendo solução de 
OLIVEIRA, J.A.; VIEIRA, M.A.; SILVA, A.C.; BARBOSA, C.A.L.; VELOSO, A.P. Ação de agentes quimicos e físicos sobre ovos de Lagochilascaris minor. Leiper,1909. Rev. Pat. Trop.24 (2): 301 - 311, jul/dez. 1995

formaldeído a $1 \%$ e deixados por um período de 45 dias à temperatura ambiente. Diariamente, todos os ovos, tanto do grupo controle como dos tratados, eram homogeneizados e oxigenados.

\section{Avaliação da eficácia}

A avaliação da eficácia foi feita pela comparação entre as percentagens de ovos férteis do grupo controle com as percentagens dos ovos férteis dos grupos tratados, aplicando-se a seguinte fórmula: ${ }^{(11)}$

$$
E \%=\frac{X C-X T}{X C} \times 100
$$

$\mathrm{E} \%=$ percentagem de efícácia da droga

$\mathrm{XC}=$ percentagem de ovos férteis do controle

$\mathrm{XT}=$ percentagem de ovos férteis do tratamento

\section{RESULTADOS}

Os resultados do presente trabalho quanto à ação de vários agentes químicos (álcool etílico, lugol, formaldeído, Hipoclorito de sódio) e agentes físicos (congelamento e aquecimento) sobre os ovos de Lagochilascaris minor, e o percentual da eficácia desses vários agentes são apresentados nas tabelas 1 a 7 .

O sulfado de zinco, utilizado no processo de separação dos ovos, não apresentou nenhuma alteração quanto à evolução dos mesmos, com relação aos tratados e aos ovos do grupo controle.

Podemos observar na tabela 2 que nas concentrações abaixo de $99^{\circ} \mathrm{GL}$ de álcool etílico não apresentou eficácia.

O formaldeído mostrou-se ineficaz para a esterilização das vidrarias, mesmo em altas concentrações (Tabela 3 ).

O lugol (iodo a 1\%), apresentou uma eficácia de $100 \%$ em todas as concentrações testadas (Tabela 4).

O hipoclorito de sódio, por destruir a membrana dos ovos, dificultou a análise matemática dos dados, pois quando se coletaram as alíquotas dos ovos tratados,
OLIVEIRA, J.A.; VIEIRA, M.A.; SILVA, A.C.; BARBOSA, C.A.L.; VELOSO, A.P. Ação de agentes químicos e físicos sobre ovos de Lagochilascaris minor. Leiper,1909. Rev. Pat. Trop.24 ( 2 ): $301-311$, jul/dez. 1995

constatou-se que grande parte foi destruída, encontrando-se várias larvas mortas e raros ovos larvados com larva viável em seu interior (Tabela 5).

$\mathrm{O}$ congelamento e o aquecimento demonstraram também serem métodos de escolha para eliminação dos ovos, principalmente dos sobrenadantes das lavagens dos ovos, no ato da confecção da cultura (Tabelas 6 e 7).

Tabela 1. Relação entre ovos férteis e inférteis submetidos ao tratamento com sulfato de zinco

\begin{tabular}{ccccccc}
\hline & \multicolumn{3}{c}{ Ovos férteis } & & \multicolumn{3}{c}{ Ovos inférteis } & \\
\cline { 2 - 3 } Concentração \% & $\mathrm{n}^{\circ}$ & $\%$ & & $\mathrm{n}^{\circ}$ & $\%$ & Eficácia \% \\
\hline $33 \%$ & 139 & 95,86 & & 06 & 4,14 & 0,0 \\
Controle & 302 & 95,27 & & 15 & 4,73 & - \\
\hline
\end{tabular}

Tabela 2. Relação entre ovos férteis e inférteis submetidos ao tratamento com álcool etílico P.A.

\begin{tabular}{cccccccr}
\hline & \multicolumn{2}{c}{ Ovos férteis } & & \multicolumn{2}{c}{ Ovos inférteis } & \\
\cline { 2 - 3 } Concentração \% G.L. & \multicolumn{1}{c}{$\mathrm{n}^{\circ}$} & $\%$ & & $\mathrm{n}^{0}$ & $\%$ & Eficácia \% \\
\hline 70 & 576 & 93,97 & & 37 & 6,03 & 2,20 \\
80 & 1023 & 90,94 & & 102 & 9,06 & 5,36 \\
90 & 258 & 58,92 & & 106 & 41,08 & 38,68 \\
99 & 0 & 0,00 & & 470 & 100,00 & 100,00 \\
Controle & 769 & 96,09 & & 30 & 3,90 & - \\
\hline * P.A. = Para Análise & G.L. Graus Gay-Lussac & & &
\end{tabular}

Tabela 3. Relação entre ovos férteis e inférteis submetidos ao tratamento com formaldeído

\begin{tabular}{|c|c|c|c|c|c|}
\hline \multirow[b]{2}{*}{ Concentração \% } & \multicolumn{2}{|c|}{ Ovos férteis } & \multicolumn{2}{|c|}{ Ovos inférteis } & \multirow[b]{2}{*}{ Eficácia \% } \\
\hline & $\mathrm{n}^{0}$ & $\%$ & $\mathrm{n}^{0}$ & $\%$ & \\
\hline $37 \mathrm{PA}$ & 168 & 80,38 & 41 & 19,62 & 14,66 \\
\hline $30 \mathrm{PA}$ & 64 & 46,38 & 74 & 53,62 & 50,76 \\
\hline $20 \mathrm{PA}$ & 166 & 92,23 & 14 & 7,77 & 2,08 \\
\hline $10 \mathrm{PA}$ & 371 & 94,78 & 21 & 5,22 & 0,00 \\
\hline $5 \mathrm{PA}$ & 252 & 96,99 & 08 & 3,01 & 0,00 \\
\hline 5 comercial & 62 & 95,38 & 03 & 4,62 & 0,00 \\
\hline Controle & 86 & 94,19 & 05 & 5,81 & - \\
\hline
\end{tabular}


OLIVEIRA, J.A.; VIEIRA, M.A.; SILVA, A.C.; BARBOSA, C.A.L.; VELOSO, A.P. Ação de agentes químicos e fisicos sobre ovos de Lagochilascaris minor. Leiper,1909. Rev. Pat. Trop.24 ( 2 ): 301 - 311 , jul/dez. 1995

Tabela 4. Relação entre ovos férteis e inférteis submetidos ao tratamento com lugol

\begin{tabular}{ccccccc}
\hline Concentração & \multicolumn{2}{c}{ Ovos férteis } & & \multicolumn{2}{c}{ Ovos inférteis } & \\
\cline { 2 - 3 } \cline { 5 - 6 } do Lugol em \% & $\mathrm{n}^{\circ}$ & $\%$ & & $\mathrm{n}^{\circ}$ & $\%$ & Eficácia \% \\
\hline 100 & 0 & 0,00 & & 156 & 100,0 & 100 \\
50 & 0 & 0,00 & & 267 & 100,0 & 100 \\
25 & 0 & 0,00 & & 294 & 100,0 & 100 \\
12,5 & 0 & 0,00 & & 273 & 100,0 & 100 \\
6,25 & 0 & 0,00 & & 380 & 100,0 & 100 \\
3,125 & 0 & 0,00 & & 285 & 100,0 & 100 \\
controle & 738 & 96,20 & & 28 & 3,8 & - \\
\hline
\end{tabular}

Tabela 5. Relação entre ovos férteis e inférteis submetidos ao tratamento com hipoclorito de sódio

\begin{tabular}{|c|c|c|c|c|c|}
\hline \multirow[b]{2}{*}{ Concentração \% } & \multicolumn{2}{|c|}{ Ovos férteis } & \multicolumn{2}{|c|}{ Ovos inférteis } & \multirow[b]{2}{*}{ Eficácia \% } \\
\hline & $\mathrm{n}^{0}$ & $\%$ & $\mathrm{n}^{0}$ & $\%$ & \\
\hline $6,13 \mathrm{~N}$ & 0 & 0,00 & 0 & 0,00 & 20 \\
\hline $4,0 \mathrm{~N}$ & 1 & $*$ & 0 & 0,00 & 26 \\
\hline $3,0 \mathrm{~N}$ & 0 & 0,00 & 0 & 0,00 & 25 \\
\hline $2,0 \mathrm{~N}$ & 0 & 0,00 & 0 & 0,00 & 18 \\
\hline $1,0 \mathrm{~N}$ & 1 & $*$ & 1 & $*$ & 28 \\
\hline $0,5 \mathrm{~N}$ & 0 & 0,00 & 1 & $*$ & 36 \\
\hline controle & 103 & 96,26 & 4 & 3,74 & 0,0 \\
\hline
\end{tabular}

* Como foi encontrada uma pequena quantidade de ovos férteis e inférteis nestas concentraçð̃es, a percentagem dos mesmos se torna um dado ilógico devido ao grande número de ovos utilizados para cada tratamento.

Tabela 6. Relação entre ovos férteis e inférteis submetidos ao tratamento por Congelamento a $\left(-10^{\circ} \mathrm{C}\right)$

\begin{tabular}{|c|c|c|c|c|c|}
\hline \multirow[b]{2}{*}{ Temperatura } & \multicolumn{2}{|c|}{ Ovos férteis } & \multicolumn{2}{|c|}{ Ovos inférteis } & \multirow[b]{2}{*}{ Eficácia \% } \\
\hline & $\mathrm{n}^{0}$ & $\%$ & $\mathrm{n}^{0}$ & $\%$ & \\
\hline$-10^{\circ} \mathrm{C}$ & 4 & 0,96 & 413 & 99,04 & 99,02 \\
\hline controle & 324 & 98,18 & 6 & 1,82 & - \\
\hline
\end{tabular}

OLIVEIRA, J.A.; VIEIRA, M.A.; SILVA, A.C.; BARBOSA, C.A.L.; VELOSO, A.P. Ação de agentes químicos e fisicos sobre ovos de Lagochilascaris minor. Leiper,1909. Rev. Pat. Trop.24 ( 2 ): 301 - 311 , jul/dez. 1995

Tabela 7. Relação entre ovos férteis e inférteis submetidos ao tratamento pelo aquecimento.

\begin{tabular}{lcccccc}
\hline & \multicolumn{2}{c}{ Ovos férteis } & & \multicolumn{2}{c}{ Ovos inférteis } & \\
\cline { 2 - 3 } & $\mathrm{n}^{\circ}$ & $\%$ & & $\mathrm{n}^{\circ}$ & $\%$ & Eficácia \% \\
\hline $97^{\circ} \mathrm{C}$ & 01 & 0,28 & & 358 & 99,72 & 99,71 \\
$90^{\circ} \mathrm{C}$ & 0 & 0,00 & & 426 & 100,00 & 100,00 \\
$80^{\circ} \mathrm{C}$ & 01 & 0,25 & & 395 & 99,75 & 99,75 \\
Controle & 324 & 98,18 & & 6 & 1,82 & - \\
\hline
\end{tabular}

\section{DISCUSSÃO}

Neste trabalho pode-se observar que o sulfato de zinco apresentou uma eficácia de $0,00 \%$, não afetando a embriogênese dos ovos e, que a separação dos ovos pela técnica de Faust e col. ${ }^{(5)}$ não interfere na evolução ou na viabilidade dos mesmos. Esses dados coincidem com MEYER et al ${ }^{(7)}$.

A ação do álcool etílico é sobre lipídios e proteínas, sendo que, desta forma, lesa membranas celulares e desnatura proteínas ${ }^{(10)}$. Sua atividade no experimento foi efetiva apenas na concentração de $99 \%$, atuando contra os ovos pré-embrionados, porém, para o uso diário se torna ineficiente pois, além do alto custo, os ovos que serão eliminados nos processos de produção da cultura estarão suspensos em água e logo, diluirá o álcool etílico para concentrações de pouca atividade sobre os ovos.

Segundo TRABULSI ${ }^{(10)}$, o formaldeído atua sobe as células provocando desnaturação protéica, reagindo como agente alquilante (formaldeído reage com grupos amino, hidroxila, carboxila e sulfidrila, introduzindo um radical $-\mathrm{CH}_{2}$ - entre grupos adjacentes, alterando as estruturas dos ácidos nucléicos e proteínas). Talvez devido à casca do ovo ou ao pequeno tempo de exposição $(24 \mathrm{~h})$ não tenha ocorrido uma maior efetividade do formaldeído sobre os mesmos. Os dados não são coincidentes com YOSCHIDA apud PESSOA ${ }^{(9)}$ onde os ovos de ascarídeos morrem a $15 \%$ de formaldeído. Como foi testada a faixa de $20 \%$ e $10 \%$, supõe-se que esta faixa de concentração não seja realmente tão efetiva no tempo estipulado. A concentração mais eficiente do formaldeído foi a $30 \%$, onde a percentagem de eficiência não passou de 50,76 e portanto, não recomendado para o tratamento proposto devido aos mesmos fatores assinalados em relação ao álcool etílico.

O Iodo provoca inativação enzimática (imediata) e reage com resíduos de tirosina, presente em proteínas, inativando enzimas celulares ${ }^{(10)}$. AGUIAR et al. ${ }^{(1)}$, observaram que o biiodeto de mercúrio preserva bem os ovos de helmintos tanto a 
$1 \%$ como a $2 \%$. Neste trabalho ocorreu uma percentagem de eficácia em todas as concentrações de $100 \%$ de letalidade para os ovos pré-embrionados. Infere-se pois, que a casca dos ovos não foi eficiente para a sua proteção, sendo este, o agente de ques resíduos das culturas de ovos. Este potencial ovicida do iodo, demonstrado neste trabalho, sugere uma provável linha de tratamento da lagochilascaríase, ainda por explorar.

O hipoclorito de sódio atua a partir do cloro livre, o qual provoca uma imationo enzimática e ação oxidante imediata ${ }^{(10)}$. MEYER. et al. ${ }^{(7)}$, observaram que o hipoclorito na concentração de $2,62 \%$ não mata nem decompõe ovos de que o hipoclorito na concentração (7) , demonstrou que o hipoclorito não é efetivo Ascaris, e BARRET apud de Ascaris quando expostos a uma solução de 7,4\% de hipoclorito por 24 horas. $\operatorname{MEYER}^{(7)}$ ainda observou que quando o hipoclorito foi usado sozinho $38 \%$ dos ovos da cultura foram recuperados.

A membrana mamilonada é destruída pela ação do hipoclorito sendo que alvez o tempo de 24 horas seja insuficiente para a destruição desta casca e atuação do cloro nas células embriogênicas do ovo. BARUFFALDI et al. ${ }^{(3)}$ observaram que a redução significativa de protozoários e helmintos, em decorrência do efeito conjugado da lavagem e desinfecção com hipoclorito, exigiram intervalos de exposição de 40 min para soluções com $30 \mathrm{ppm}$ de cloro livre disponível e maior ou igual a $10 \mathrm{~min}$ à concentração de $40 \mathrm{ppm}$ de cloro livre disponível. Neste experimento observou-se, após 45 dias de cultura, que houve uma redução no número de ovos, sendo que estes apresentavam-se sem a membrana mamilonada e com presença de larvas viáveis em seu interior (confirmada após compressão entre lâmina e lamínula). Nenhum ovo infértil e dezenas de larvas mortas, livres na suspensão, foram encontrados. Por um lado o hipoclorito foi eficiente devido ao fato de reduzir drasticamente o número de ovos, porém, sua ineficácia apoia-se na observação de que o mesmo não impediu a embriogênese. Podemos inferir a partir destes dados que o hipoclorito destruiu as membranas dos ovos e não impediu sua embriogênese. Sua eficácia pode ser excelente, se aumentado o tempo de exposição nos ovos, porém inadequado para o uso no laboratório porque a vidraria ficaria sem utilização por mais de um dia.

Quanto à exposição por agentes físicos, (congelamento e aquecimento) foi observada uma eficácia próxima de $100 \%$ tanto na congelamento como pelo aquecimento na faixa de 80 a $97^{\circ} \mathrm{C}$. Deve-se levar em consideração, em relação ao aquecimento, que não houve um temperatura constante por 24 horas pois, a água aquecida era colocada sobre os ovos nos tubos de ensaios e mantida assim até atingir a temperatura ambiente, que ocorria pelo menos em 1 hora. Supõe-se que, se fosse mantida esta temperatura por 10 minutos ou mais, ocorreria $100 \%$ de eficácia sobre estes ovos. Observação pertinente foi feita por MARTINS ${ }^{(6)}$ que durante
OLIVEIRA, J.A.; VIEIRA, M.A.; SILVA, A.C.; BARBOSA, C.A.L.; VELOSO, A.P. Ação de agentes químicos e físicos sobre ovos de Lagochilascaris minor. Leiper,1909. Rev. Pat. Trop.24 ( 2 ): 301 - 311, jul/dez. 1995

esterilização e destruição de patógenos em lodo digerido não conseguiu uma maior efetividade da temperatura devidas às dificuldades de mantê-la adequada. Conforme $\operatorname{PESSOA}^{(9)}$ quanto mais for elevada a temperatura mais fraca será a resistência dos ovos à dessecação. De 5 a $25^{\circ} \mathrm{C}$ em meio seco, a resistência dos ovos de Ascaris não ultrapassa a 3 meses. De acordo com KALBE apud PESSOA ${ }^{(9)}$, temperaturas mais elevadas são nocivas, mesmo em meio úmido, sendo que os ovos resistem bem em meio frio.

\section{CONCLUSÕES}

De acordo com os dados obtidos neste trabalho podemos concluir que:

1. O sulfato de zinco não interfere na viabilidade dos ovos.

2. O álcool etílico é efetivo na concentração de $99 \%$ porém sem utilização para o tratamento proposto.

3. O formaldeído é ineficaz em todas as concentrações testadas, sendo que sua maior atividade ovicida é na concentração de $30 \%$.

4. O lugol demonstrou ser o agente ideal na esterilização dos dejetos, sendo que sua atividade ovicida foi de $100 \%$ em todas as concentrações. Esta atuação em baixas concentrações in vitro estimula sua utilização in vivo no tratamento da lagochilascaríase.

5. O hipoclorito mostrou-se ineficiente aos objetivos propostos devido ao fato de não impedir a embriogênese e ainda facilitar a liberação da larva no meio externo.

6. Tanto o tratamento pelo aquecimento como pelo congelamento foi eficaz e portanto, recomendado para o uso na desinfecção dos ovos de L. minor. 

310
OLIVEIRA, J.A.; VIEIRA, M.A.; SILVA, A.C.; BARBOSA, C.A.L.; VELOSO, A.P. Ação de agentes
, químicos e fi jul/dez. 1995

\section{SUMMARY}

In vitro effect of chemical and physical agents on viability and embriogenesis of eggs of Lagochilascaris minor (Leiper, 1909).

Various chemical agents (ethilic alcohol, formaldehyde, lugol in different concentrations) have had their efficacy tested against Lagochilascaris minor eggs. The eggs were also submitted to physical agents (freezing $-10^{\circ} \mathrm{C}$, heating $80 / 97^{\circ} \mathrm{C}$ ). The lethality index was calculated through the embriogenesis rate. The following The letions tested yield a $100 \%$ lethality index: $90^{\circ} \mathrm{C}$ heating, $99 \%$ ethilic alcohol and lugol $(100 \%, 50 \%, 25 \%, 6,25 \%, 3,125 \%)$.

KEYWORDS: Lagochilascaris minor. Chemical and physical agents. Helmints eggs.

\section{REFERÊNCIAS BIBLIOGRÁFICAS}

01.AGUIAR, P.R.; VENTURA, V.R.; BURKART, I.H.V.; NASCIMENTO, J. A.; LIMA, I A como preservativo de material biológico. Rev. Inst. Adolfo Lutz, 41 ( 1 ): 47-52, 1981.

2 AMARAL, A.DF; LEAL, R.A. Sobre o encontro de ovos viáveis de Ascaris lumbrich trichura em adubo constíduos de lumbricoides e de Trichu e Higiene, 11 ( 1 ) : 35-39, out. 1940. 03.BARUFFALDI, R.; PENNA, T. C. V.; MASCHOSHVILI, I. A.; ABE, L. E.
Tratamento químico de hortaliças poluídas. Rev. Saúde Públ., São Paulo, 18: $225-34,1984$.

04.CAMPOS, D.M.B.; FREIRE FILHA, L.G.; VIEIRA, M.A.; PAÇÔ J.M.; MAIA M.A. Experimental life cycle of Lagochilascaris minor Leiper 1909. Rev. Inst. Med. trop. São Paulo, 34:277-87, 1992.

05.FAUST, E.C.; D'ANTONI, J. S.; ODOM, V.; MILLER, M. J.; PERES, C.; SAWITZ, W. THOMEN, L. F. TOBIE, J. \& WALDER, J. H. A critical SAWITZ, W.; THOMEN, L. F.; TOBIE, J. \& WALD
study of clinical laboratory technics for the diagnosis of protozoan cysts and
OLIVEIRA, J.A.; VIEIRA, M.A.; SILVA, A.C.; BARBOSA, C.A.L.; VELOSO, A.P. Ação de agentes químicos e físic; jul/dez. 1995

helminth eggs in feces. I. Preliminary communication. Amer. J. Trop. Med., 18: $169-83.1938$.

06.MARTINS, M.T., Eficácia do tratamento químico e térmico na destruição de patógenos em lodo digerido. Rev. Microbiol. São Paulo, 17 ( 2 ): 148-154, abr./jun. 1986.

07.MEYER, K. B.; MILLER, K.D. \& KANOSHIRO, E.S.; Recovery of Ascaris eggs from Sludge. J. Parasitol. 64 ( 2 ): 380-83, abr. 1978.

08.LEVAI, E. V.; AMATO NETO, V.; CAMPOS, R.; PINTO, R. L. S.; MOREIRA, A. A. B.; SANT'ANA, E. J.; PADILHA, L. A. A.; Pesquisa de ovos de helmintos e de cistos de protozoários em dinheiro. Rev. Saúde Públ. São Paulo, 20 (1): 33-6, 1986.

09.PESSOA, S. B.; MARTINS, A. V., Pessoa Parasitologia Médica. Ed. Guanabara Koogan, $9^{a}$ edição, p. 669-674, 1974.

10.TRABULSI, L.R. Microbiologia. Ed. Livraria Atheneu, $2^{\mathrm{a}}$ edição, p. 99-102, 1989.

11. VIEIRA, M. A.; SILVA, A.C.; FREIRE FILHA, L. G.; BARBOSA, C. A. L. ; CAMPOS, D. M. B. Avaliação da eficácia do ivermectin na larva migrans murina experimental. Rev. Pat. Trop., 22 ( 1 ): 1-8, jan. / jun. 1993. 